\title{
USABILITY, STRENGTH AND PRACTICALITY OF THE UPCOMING HYSPIRI IN DETECTING MAIZE GRAY LEAFY SPOT IN RELATION TO SENTINEL-2 MSI, VEN $\mu S$ AND LANDSAT 8 OLI SPECTRAL BAND-SETTINGS
}

\author{
M Sibanda ${ }^{1}$, O Mutanga ${ }^{1}$, T Dube ${ }^{2}$, John Odindi ${ }^{1 *}$ and P L Mafongoya ${ }^{1}$ \\ ${ }^{1}$ University of KwaZulu-Natal, School of Agricultural, Earth and Environmental Sciences, Geography Department, \\ Pietermaritzburg, South Africa, Private Bag X01, 3209; (Sibandam3@ukzn.ac.za, MutangaO@ukzn.ac.za ; Odindi@ukzn.ac.za \\ ${ }^{2}$ Institute for Water Studies, Dept of Earth Sciences, The University of the Western Cape, Private Bag X17, Bellville 7535, \\ South Africa; tidube@uwc.ac.za
}

Commission VI, WG VI/4

KEYWORDS: Hyperspectral data, maize, crop diseases, PLS-DA

\begin{abstract}
Considering the high maize yield loses that are caused by diseases incidences as well as incomprehensive monitoring initiatives in the crop farming sector of agriculture, there is a need to come up with spatially explicit, cheap, fast and consistent approaches for monitoring as well as forecasting food crop diseases, such as maize gray leaf spot. This study, therefore, we sought to investigate the usability, strength and practicality of the forthcoming HyspIRI in detecting disease progression of Maize Gray leafy spot infections in relation to the Sentinel-2 MSI, Landsat 8 OLI spectral configurations. Maize Gray leafy spot disease progression that were discriminated based on partial least squares -discriminant analysis (PLS-DA) algorithm were (i) healthy, (ii) intermediate and (ii) severely infected maize crops. Comparatively, the results show that the HyspIRI's simulated spectral settings slightly performed better than those of Sentinel-2 MSI, VEN $\mu$ S and Landsat 8 OLI sensor. HyspIRI exhibited an overall accuracy of 0.98 compared to $0.95,0.93$ and 0.89 exhibited by Sentinel-2 MSI, VEN $\mu$ S and Landsat 8 OLI sensor sensors, respectively. Further, the results showed that the visible section the red-edge and NIR covered by all the four sensors were the most influential spectral regions for discriminating different Maize Gray leafy spot infections. These findings underscore the added value and potential scientific breakthroughs likely to be brought about by the upcoming hyperspectral HyspIRI sensor in precision agriculture and forecasting of crop disease epidemics to ensure food security.
\end{abstract}

\section{INTRODUCTION}

Maize is one of the most important crops in the world offering $30 \%$ of the food calories to above 4.5 billion people mostly in developing economies (FAOSTAT 2010). Approximately, $67 \%$ of the total maize production in developed countries is primarily produced by low and middle income developing countries (FAOSTAT 2010). In that regard maize plays a critical role in fostering food security as well as in contributing to the gross national income of developing countries. Although in the African context maize is a critical source of food, its demand as principal element of livestock feeds is still growing in America Asia and the Middle East Africa (Shiferaw et al. 2011). The production of maize has however, largely been stalled by pest and diseases that tend to affect maize crops during the growing, post harvesting processing and storage stages.

Leafy gray spot (GLS) is one of the major diseases that adversely affects crop maize production in the Southern Africa context. This maize disease is caused by a fungus known as Cercospora zeae-maydis which affects maize crops across all the phenological stages. According to Dhami et al. (2015), Cercospora zeae-maydis is a polycyclic facultative pathogen or fungi, which survives as mycelium in the residues of infected maize crops after harvesting. The GSL disease typically starts in spring during the green-up phenological stage of maize plants when the conidia is transferred to new plants by wind and splashing rain water. The conidia (spores) infect the maize crops through the stomatal openings of leaves. Approximately two to three weeks after colonizing the tissues of maize leaves, gray to tan lesions grow between the leaf veins giving them a narrow, rectangular appearance which are $5-70 \mathrm{~mm}$ long by $2-4 \mathrm{~mm}$ wide (Dhami et al. 2015). These lesions ultimately sporulate, spread and coalesce covering the entire surface areas of leaves. Subsequently, these lesions excessively reduce the level of sugar causing stalk lodging which ultimately results in premature death of maize crops as well as extreme yield losses of up to $100 \%$ (Dhami et al. 2015). In this regard, GLS is widely recognized as the most significant yieldlimiting disease in maize crop production (Ward et al. 1994, Geis 2014).

The emergence of this fungus was first noted in the samples collected in the state of Illions, United States of America by Tehon and Daniels (1925). GLS was and is still recognized as the most severe, destructive and yield limiting maize and corn disease especially when its incidences manifested at a large spatial extent in the maize growing states of America (Dhami et al. 2015). In South Africa GLS was first recorded between 1988-89 in Grey town and in 1992 at Cedara in KwaZulu Natal Province (Gevers et al. 1994, Ward et al. 1994, Ward et al. 1999). During the period of 1991 to 1992, GLS attained epidemic level status in South Africa resulting in $13 \%$ grain yield losses in trials located in KwaZulu Natal, south Africa. Economic losses associated with GSL for that period were estimated to be 
between R1554 and R2278 ha-1 depending on the level of inherent disease resistance (Nowell 1996). Since then the disease manifested into a pandemic which rapidly proliferated to other provinces in South Africa as well as other countries in Sub-Saharan Africa (Ward et al. 1999). Therefore, efficient novel techniques for forecasting pandemics similar to GLS are still urgently required to foster food security especially in the developing countries in Sub-Saharan Africa which where maize farming is the mainstay of millions of livelihoods.

It is currently a common practice for farmers to rely on field surveys in monitoring the health of agricultural crops such as maize especially in developing countries (Gao et al. 2017). Furthermore, the administration of agro-chemicals to treat fungal pathogen disease such as GLS, is also currently conducted in an indiscriminate manner which results in exorbitant economic losses associated with purchasing and applying fungicides. Even more so, the estimation of damages associated with such epidemic crop diseases, their spatial extent as well as their real time spatial distribution have largely been contingent on physical surveys. Techniques such as physical surveys have proved to be highly subjective especially at landscape scales while being tedious and relatively time consuming (Gao et al. 2017). Subsequently, there is need for cheap, fast and consistent methods for agricultural crop disease monitoring as well as forecasting of related food crop diseases so as to fostering food security while reducing the associated economic losses as well as environmental pollution from indiscriminate administration of pesticides.

To date, earth observation techniques have been widely proven to be an effective non-invasive non-destructive and autonomous tool for detecting and monitoring biotic and abiotic stress in agricultural crops at local to regional scales and different phenological stages (Thenkabail et al. 2002, Lowe et al. 2017, Bégué et al. 2018). The success of remotely sensed data in monitoring and forecasting crop diseases such as GLS stem from its synoptic views which are characterized by spatially explicit, continuous and abundant wavebands which are timely acquired such that they have the ability to capture subtle biochemical and physical changes of crop plants. Earth observation sensors record the spectral reflectance of plant canopies of both infected and healthy crops. Subsequently, the spectral signature of infected crops tends to be different from that of healthy crops due to the biochemical and physiological alterations caused by crop diseases such as GLS (Chaerle and Van Der Straeten 2000, Mee et al. 2017). The infection on crop plants result in the alteration of spectral reflectance mainly due to the perpetual diminution of chlorophyll content as well as the modification of internal tissue structure which in turn results in physiological changes in the canopy of the crops (Mee et al. 2017). When a plant is infected, the disease stress reduces the chlorophyll concentration which results in increased reflectance in the red region of the electromagnetic spectrum (EMS)(Mee et al. 2017). Comparatively, healthy crop plants are associated with a high reflectance in the green and near infrared spectrums and low reflectance in the red and blue spectrums (Mee et al. 2017). Furthermore, the increase in the magnitude of infection specifically alters numerous leaf optical properties such the leaf angle distribution (LAD), leaf area index (LAI) as well as the biomass of a plants which directly influence and determine the target-energy interactions (i.e. energy absorption, reflectance and transmission) in remote sensing vegetation. Subsequently, maize crop farming could benefit from the timeous, spatial explicit wall-to wall detection and monitoring system offered by remote sensing techniques in reducing cost as well as ensuring food security (Zhang et al. 2003).

Hyperspectral remotely sensors have been proven to be the most robust and accurate sources of remotely sensed data in vegetation mapping studies with particular reference to agricultural crops (Zhang et al. 2003, Calderón et al. 2015) For instance, Calderón et al. (2015) illustrated that hyperspectral remotely sensed data could accurately discriminate Verticillium Wilt diseases on olive crops with optimal overall accuracies of 71.4 and $75.0 \%$ at the initial and severe stages of infection. Dhau et al. (2018) also showed that hyperspectral data combined with guided regularized random forest plausibly discriminated maize crops under different levels of maize streak virus infection to an overall accuracy of $95.83 \%$. The high accuracies discrimination of crops at different levels of infection associated with hyperspectral data are attributed to its narrow spectral channels, which have the ability to capture minute spectral variations induced by crop diseases at various stages which are otherwise masked out by broad multispectral sensors. Although, hyperspectral data is renowned for its sensitivity in studying remote sensing crop traits, it is often associated with exorbitant acquisition expense and high dimensionality while it is limited to local scale applications. The redundancy associated with high dimensionality makes it challenging to process (Mariotto et al. 2013, Thenkabail et al. 2013). Due to these shortcomings as well as the rapid development of sensor technologies, the emergence of freely available broad band sensors has raised a lot of interest from the earth observation community in favor of sensors missions such as Landsat. Specifically, Landsat Operational Land imager (OLI) launched in the recent past, has been of significant interest in agricultural crops mapping studies. Although Landsat data satisfactorily performed in mapping remote sensing agricultural crop traits at landscape scales, its broad wavebands did not adequately cover portions of the EMS that are critical in vegetation mapping such as the red edge. This limitation resulted in the emergence of Sentinel-2 mulstispectral imager (MSI) as well as the forth coming Vegetation and Environment monitoring on a New MicroSatellite $(\mathrm{VEN} \mu \mathrm{S})$ as better alternatives in remote sensing crop diseases such as GSL since they cover the red edge region of the EMS. Furthermore, the earth observation community is eagerly awaiting for hyperspectral sensors which will offer spatial data freely at relatively large scales such as the National Aeronautics and Space Administration's (NASA) Hyperspectral InfraRed Imager (HyspIRI) which could circumvent the challenge saturation associated with al broad band sensors (Mariotto et al. 2013).

The HyspIRI sensor will be characterized by two instruments with an intelligent payload module: Visible/near infrared/Shortwave InfraRed (VSWIR) imaging spectrometer and a thermal infrared (TIR) 
multispectral imager. This low earth orbit sensor will offer data at temporal resolution of 5-16 days, spatial resolution of 30-60m and a global coverage (Lee et al. 2015). Above all the VSWIR instrument will offer $10 \mathrm{~nm}$ narrow contiguous wavebands, which are perceived to be sensitive the detection and mapping of crop diseases so as to increase yields and surpass food insecurities. Hyperspectral sensors such as HyspIRI offer specific narrow spectral channels, which are suitable for targeted monitoring of specific optical biochemical and physical plant parameters before and after infection by diseases at relatively low costs. Nonetheless, there is still a highly significant knowledge gap in the full exploitation of hyperspectral remotely sensed data especially in the crop farming sector of agriculture. Since the inception of the NASA's HyspIRI mission, there has been a call for comparative studies to assess the performance of HyspIRI's spectral settings and other hyper and multispectral sensors so as to advance our knowledge and models in vegetation health characterization (Mariotto et al. 2013). It is against this background that this study seeks to assess the strength and the practicality of HyspIRI's spectral configuration in detecting and discriminating maize crops at various levels MGL diseases infection levels in relation that of Sentinel-2MSI, VEN $\mu$ S and Landsat OLI.

\section{METHODS AND MATERIALS}

\subsection{Crop description and Experimental site}

Zea mays $L$ (maize) is a staple cereal crop produced in eight provinces of South Africa as a staple food of generally all South Africans and a major feed grain for subsistence, as well as a commercial product. For instance, during the
2016 to 2017 growing season, a yield of about 8 million tons of maize planted in 2629 million ha across the country produced an income of R29 659 million (DAFF 2018). The crops for this study were grown at Cedara College of Agriculture in KwaZulu Natal South Africa $\left(29^{\circ} 32^{\prime} 0^{\prime \prime}\right.$ South, $30^{\circ} 16^{\prime} 0^{\prime \prime}$ East). Cedara is situated entirely in the Moist Midlands Mist belt of KwaZulu Natal province in South Africa. This area is characterized by an altitude which ranges between $900-1400 \mathrm{~m}$ above sea level. It is a hilly and rolling country with a high percentage of arable land (i.e. $47 \%$ is of the area is suitable for cropping). Soils are relatively deep, highly leached and strongly acid. Fertility is low, but physical properties are favorable. Mean maximum January temperature for the research station is $25^{\circ} \mathrm{C}$, while mean minimum July temperature is $4^{\circ} \mathrm{C}$. This area is generally rich in water resources with rainfall of about $900 \mathrm{~mm} /$ annum.

The crops were planted on the $25^{\text {th }}$ of February 2014 under the evaluation/supervision of an agronomist. The spectral measurements were conducted during the peak phenological stage of maize growth. Infected maize crops were visually assessed and determined with aide of agronomists. Figure 2 ( $\mathrm{a}, \mathrm{b}$ and $\mathrm{c})$ illustrates the samples characterized as the healthy, moderate and severely infected stages, respectively. The leaves that had exhibited no traces of GLS lesions were referred to as "healthy" plants while leaves that had $10-42 \%$ lesions were referred to as "moderate"-ly infected and leaves which exhibited 43 to $100 \%$ coverage by GLS lesions were referred to as infected in this study. Spectral reflectance measurements were recorded in and labeled in the same manner. 

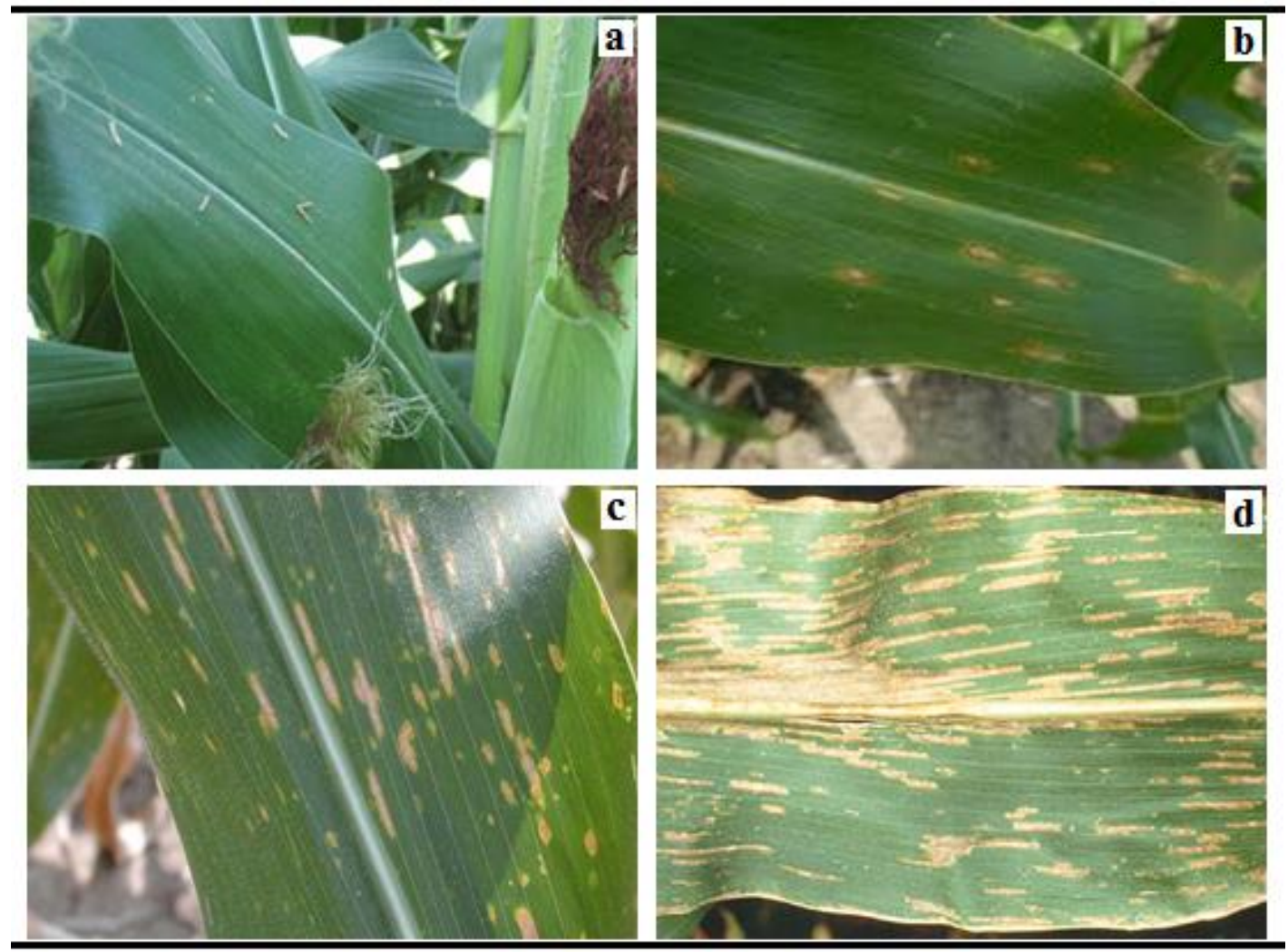

Figure 2: Maize leaves that are (a) healthy, (b, c) intermediately and (d) severely infected by Grey Leaf Spot disease.

\subsection{Remotely sensed data}

An analytical spectral device (ASD) FieldSpec ${ }^{\circledR} 4$ optical sensor (Analytical Spectral Devices, Inc., Boulder, CO, USA) was used to measure the spectral reflectance of maize crops under different levels of GLS disease infections. Reflectance measurements were recorded at $1.4 \mathrm{~nm}$ intervals between the regions 350 to $1000 \mathrm{~nm}$ as well as $2 \mathrm{~nm}$ intervals between the regions 1000 to $2500 \mathrm{~nm}$. Bare fiber optic linked to the ASD instrument was held at near nadir position at the canopies of maize plants under different levels of infection. Fifty-three spectral samples were measured under each level of infection (total samples $n=156$ ). Spectral measurements were conducted between the period of 1000 and 14000 hours under clear sky conditions since that is the time of the day with maximum net radiation from the sun. The spectra were then resampled to the spectra settings of HyspIRI, Sentinel-2 MSI, Venus and Landsat OLI sensors.

\subsection{Statistical analysis}

A two phased approach was adopted in this study to determine the strength of HyspIRI in relation to Sentinel-2 MSI, Venus and Landsat OLI spectral settings in statistically discriminating maize crops that are healthy, intermediately and severely infected by Grey Leaf Spot disease. On the first phase analysis of variance was conducted in discriminating the reflectance of maize crops under different GLS infection levels across the four spectral settings. On the second phase partial least squares discriminant analysis (PLS-DA) was used to discriminate the reflectance of maize crops under different GLS infection levels based on the spectral settings of the four sensors. PLS-DA was selected and used in this study because it has the ability to circumvent high dimensionality associated with hyperspectral datasets, such as that of HyspIRI while reducing the risk of overfitting models. Above all, PLS-DA has the ability to discern on the most influential variables in the latent factors with optimal discriminations.

\subsection{Accuracy assessment.}

Prior to discrimination based on PLS-DA, the data were split into $70 \%$ training and $30 \%$ testing datasets. The cross validated confusion matrices were derived and used to compute the overall, user and producer accuracies for the four sensors' spectral settings. In that regard the overall, user and producer accuracies were used in assessing the strength of HyspIRI's spectral configuration in detecting and discriminating maize crops at various levels MGL diseases infection levels in relation that of Sentinel-2MSI, $\mathrm{VEN} \mu \mathrm{S}$ and Landsat OLI. Furthermore, Pontius Jr and Millones (2011) quantity disagreement and allocation disagreement were also used in characterizing the performance and as well as the strength of these HyspIRI's spectral settings in relation to that of Sentinel-2MSI, VEN $\mu$ S and Landsat OLI. 


\section{RESULTS}

The ANOVA results showed that there were significant differences $(p=0.005)$ between the healthy intermediately and infected maize crops based on data resampled to the spectral settings of HyspIRI, Sentinel-2MSI, VEN $\mu$ S and Landsat OLI. Figure 2 illustrate the differences in the means of healthy intermediately and infected maize crops. Windows of spectral separability between the reflectance of healthy intermediately and infected maize crops were exhibited in the red-edge as well as in the near infrared sections of the EMS based on the spectral settings of all the sensors (Figure 2).

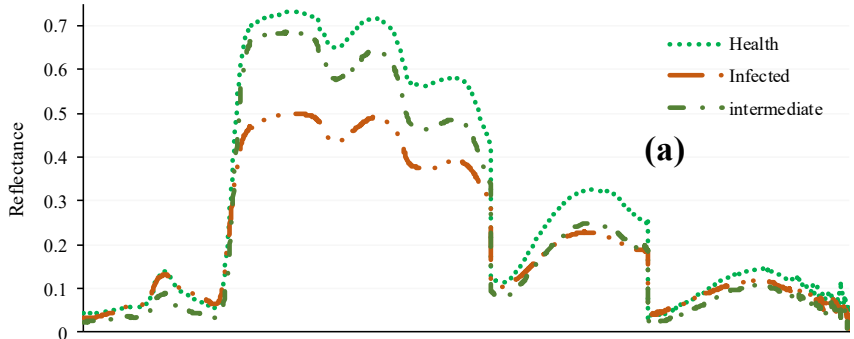

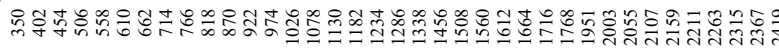
Wavebands (nm)
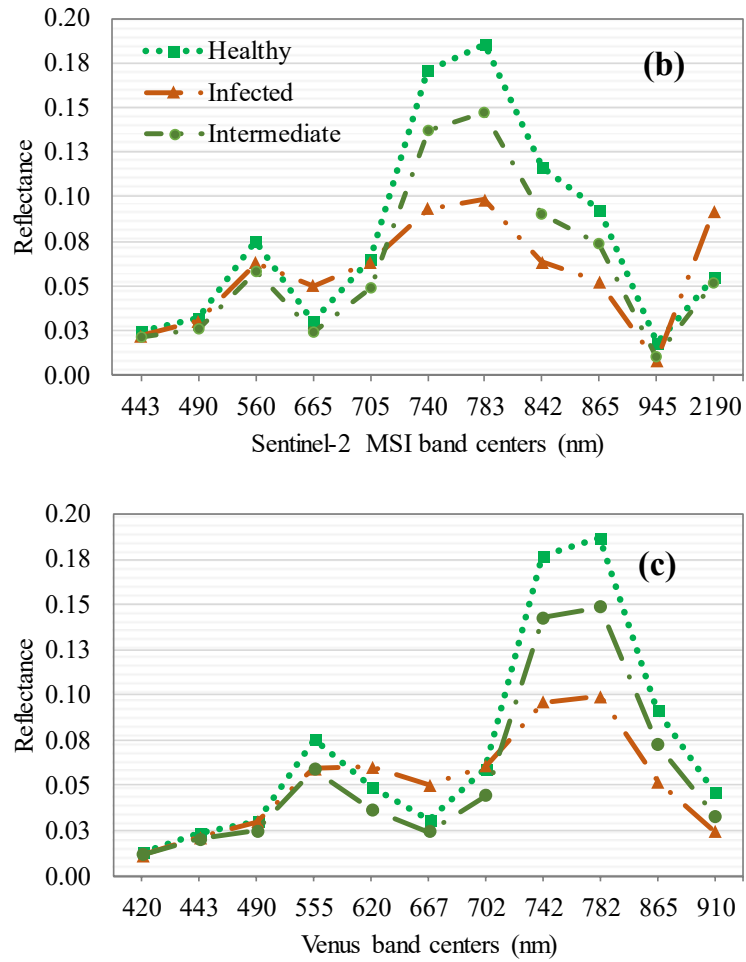

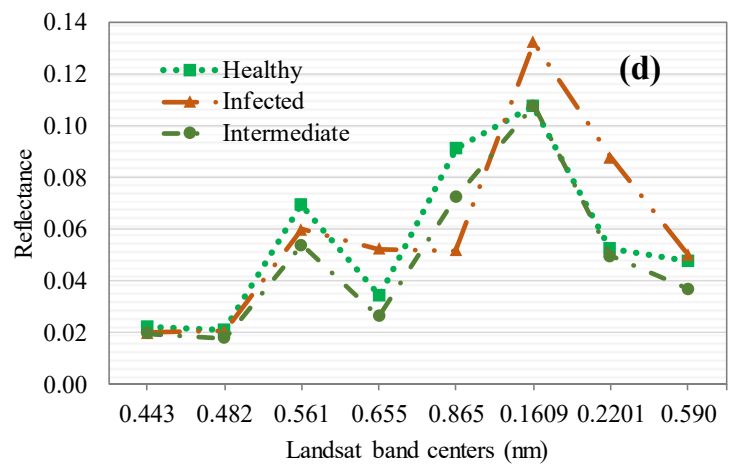

Figure 3: Differences in mean reflectance of healthy, Infected and intermediately infected maize crops based on (a) HyspIRI, (b) Sentinel-2 MSI, (3) VEN $\mu$ S and (d) Landsat OLI spectral settings.

In discriminating the different stages of GSL infection on maize using PLS-DA our results indicated that HyspIRI exhibited higher classification accuracies in relation to the other sensors considered in this study (Figure 2). Specifically, HyspIRI exhibited an overall accuracy of 0.99 , a producer and user accuracy of 99 for the healthy and infected maize crops respectively. The user accuracy of the intermediately infected crops exhibited a slightly lower user accuracy of 0.94 in relation to the other two infection levels. When using Sentinel-2 MSI spectral settings, accuracies comparable to those of HyspIRI were obtained in this study (overall accuracy 0.95). Only the user accuracies for the intermediately and severely infected were below 0.95 when Sentinel 2 MSI spectral settings were used. A similar trend was observed when using the spectral settings of VEN $\mu \mathrm{S}$ sensor. However, the user accuracies for the intermediately and severely infected further decreased to less than 0.9 when $\mathrm{VEN} \mu \mathrm{S}$ spectral settings were used. The VEN $\mu \mathrm{S}$ spectral setting yielded an overall classification accuracy of 0.94 . A different trend was observed when using the Landsat 8 OLI spectral settings. High user and producer accuracies of 1.0 were exhibited by the Landsat OLI spectral settings the infected maize crops where as those for the healthy and the intermediately infected maize crops were relatively lower those exhibited by the HyspIRI, Sentinel-2 MSI and VEN $\mu \mathrm{S}$ spectral settings. The overall accuracy exhibited by Landsat 8 OLI was 0.89 . 

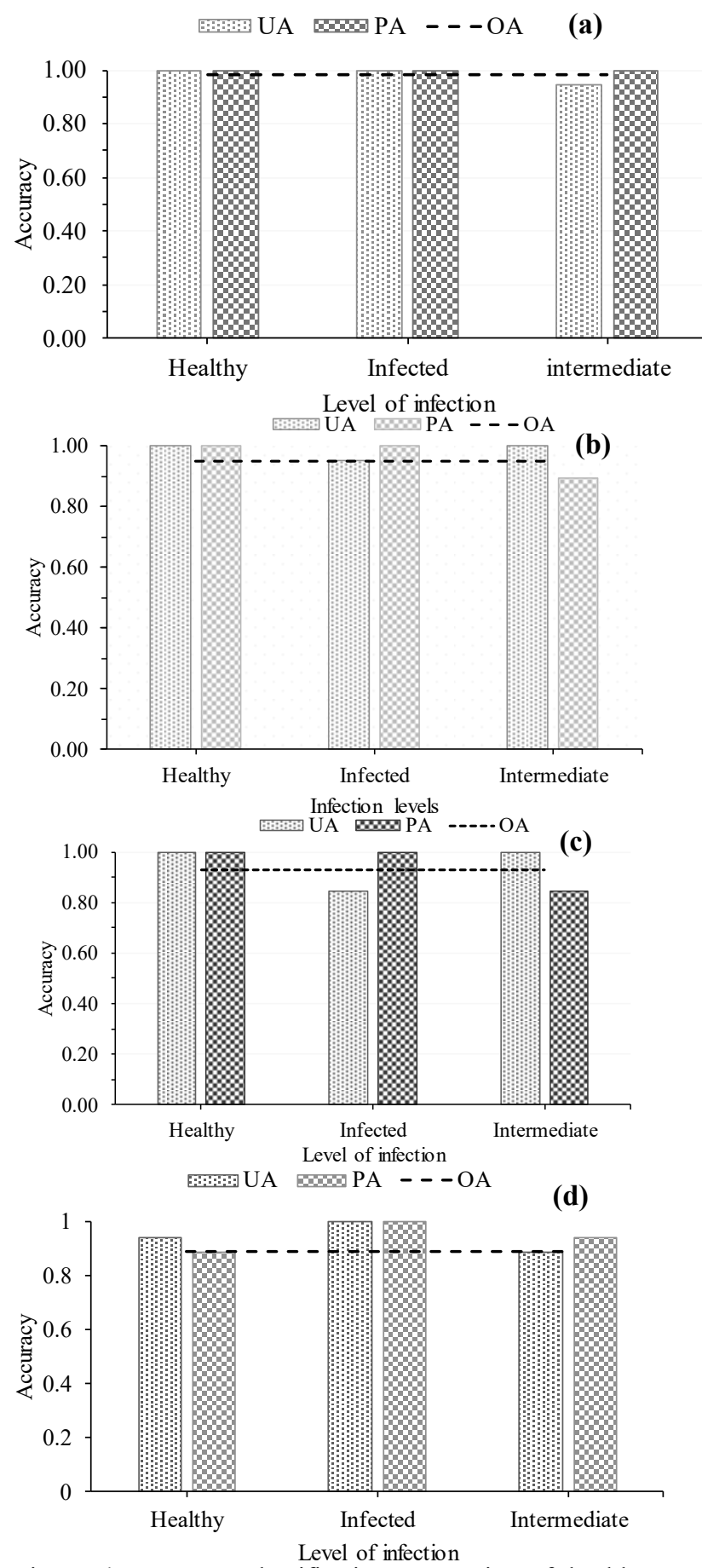

Figure 4: PLS-DA classification accuracies of healthy, Infected and intermediately infected maize crops based on (a) HyspIRI, (b) Sentinel-2 MSI, (c) VEN $\mu \mathrm{S}$ and (d) Landsat OLI spectral settings.

When assessing the accuracy and strength of HyspIRI spectral configurations in relation to those of Sentinel$2 \mathrm{MSI}, \mathrm{VEN} \mu \mathrm{S}$ and Landsat OLI based on the allocation of agreement commission and omission, results of this study showed that HyspIRI was stronger and more accurate in discriminating different GLS levels in maize crops.
Specifically, HyspIRI exhibited less than 5\% allocations of disagreement (commission) for the infected only and optimal allocations of agreement for all the GLS infection levels. Again a similar trend was of a considerable magnitude of the allocation of disagreement (omission) was observed based on the Sentinel-2 MSI and VEN $\mu$ S sensor settings for the severely 'infected' maize crops. When using Sentinel-2 MSI sensor's settings, the omission increased to above $5 \%$ and to about $8 \%$ when using the spectral setup of $\mathrm{VEN} \mu \mathrm{S}$ sensor. When Landsat OLI's spectral setup was used, the magnitude of omission and commission for the healthy and intermediately infected maize crops increased significant by a magnitude above $10 \%$ combined.

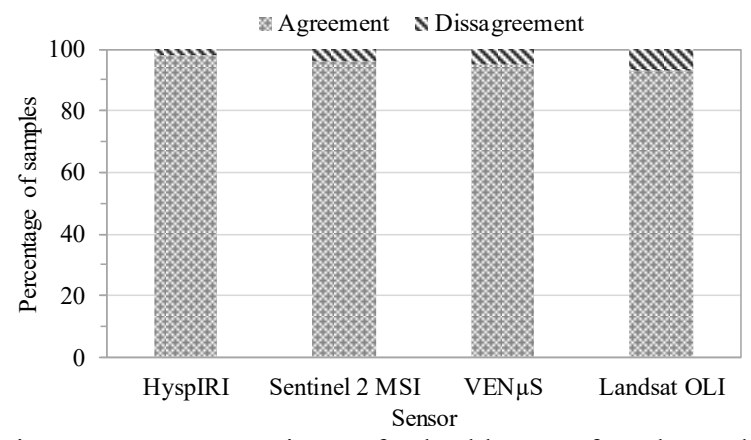

Figure 5: Accuracies of healthy, Infected and intermediately infected maize crops based on HyspIRI, (b) Sentinel-2 MSI, VEN $\mu$ S and Landsat OLI spectral settings based on Pontius and Millionres's disagreement and agreement allocations.

The most optimal wavebands that were instrumental and influential in making HyspIRI stronger and better in discriminating different levels of GLS infections in maize were from the red, red edge, mid as well as the far infrared spectral regions. Specifically, the FIR wavebands between 1995 and $2065 \mathrm{~nm}$ followed by the red edge section were the highest in terms of variable importance in projection scores. When Sentinel-2 MSI spectral settings were used, NIR band centered at $945 \mathrm{~nm}$, the red edge band centered at $740 \mathrm{~nm}$ as well as the NIR bands centered at 783 and 842 and $865 \mathrm{~nm}$ were the most influential variables. Again, VEN $\mu$ S's wavebands from the red edge and NIR region centered at $945,740,842$ and $783 \mathrm{~nm}$ in order of importance were the most influential variables in discriminating different levels of GLS infections on maize crops. Meanwhile, Landsat OLI's bands 7, 4, 5 and 6 were the most influential variables.

\section{DISCUSSION}

The prime objective of this study was to the evaluate the strength of HyspIRI's spectral configuration in detecting and discriminating maize crops at various levels GLS diseases infection in relation that of Sentinel-2MSI, VEN $\mu \mathrm{S}$ and Landsat OLI.

The spectral setup of HyspIRI emerged to be more robust and accurate in classifying healthy maize crops from those that were intermediately, as well as severely infected by 
GLS in relation to the spectral settings of Sentinel-2MSI, VEN $\mu \mathrm{S}$ and Landsat OLI. Literature underscores the narrow widths of hyperspectral wavebands in vegetation discrimination as the reason for their optimal performance when compared with broad wavebands which tend to mask out critical fine grained information that is instrumental in discrimination infected crops from healthy ones (Mutanga et al. 2009, Thenkabail et al. 2013, Marshall and Thenkabail 2015). This explains the optimal performance of HyspIRI in relation to the other three sensors.

Specifically, Sentinel-2MSI, VEN $\mu$ S and Landsat OLI have broader wave bands characterized by widths which range from 15 to $115 \mathrm{~nm}$. These wave bands tend to be insensitive to the optical traits that are altered by the diseases such as the GLS resulting in them being insensitive to the infected crop's optical canopy traits. This explains the less accuracies exhibited by sensors such as Landsat OLI in this study (Dhau et al. 2018).

Results of this study showed that the performance of Sentinel-2 MSI was comparable to that of HyspIRI and yet it was not significantly different from that of VEN $\mu S$. However, Sentinel-2 MSI performed better than Landsat OLI, which exhibited the least classification accuracies. Although, Sentinel-2 MSI does not have spectral channels that are as narrow as those of HyspIRI it covers the red edge which are not covered by Landsat OLI sensor. This could explain the optimal performance of Sentinel-2 when compared with Landsat OLI sensor's spectral setup. When comparing the spectral setup of Sentinel-2 MSI there slightly less variations in terms of the EMS regions covered by both these sensors hence their almost similar performance in discriminating different levels of GSL disease in this study. Above the bands widths of Landsat OLI when compared to those of Sentinel-2 MSI are slightly broad, masking out even more information that is critical in discriminating maize crops at various GLS infection levels. Results of this study validate the theoretical discourse put forth by (Marshall and Thenkabail (2015)) which emphasizes the importance of high spectral resolution as opposed to high spatial resolution particularly on sensors that cover the red edge section of the EMS when HypIRI outperformed Sentinel-2MSI, VEN $\mu$ S and Landsat OLI.

HyspIRI's NIR and red edge bands were more influential variables in discriminating maize crops under different levels of GLS infections. The optimal performance of HyspIRI's spectral settings could be explained by its contiguous $10 \mathrm{~nm}$ narrow wavebands which are sensitive in detecting the subtle changes in the biochemical and physiological changes induced by the GLS on maize crops. Meanwhile, the GLS lesions in maize crop leaves after infection and reducing chlorophyll concentration could be shifting the red edge position towards the short wavebands facilitating optimal discriminations especially when using narrower spectral channels in relation to broad wavebands. In the study by Dhau et al. (2018) the hyperspectral, which were noted to be highly influential in discriminating maize crops under various stages of maize streak virus infections were in the visible $(552 \mathrm{~nm}, 603 \mathrm{~nm})$ and NIR $(881 \mathrm{~nm}$ and $2338 \mathrm{~nm}$ ) spectral sections of the EMS. Meanwhile, (AlAhmadi et al. (2018)) demonstrated that the narrow spectral channels of hyperspectral data particularly the NIR band
1940 optimally detected Macrophomina phaseolina toxin effects in soybean as is the case in this study.

\section{CONCLUSIONS}

We tested the strength and practicality of HyspIRI's spectral configuration in detecting and discriminating maize crops at various stages of GLS diseases infection in relation that of Sentinel-2MSI, VEN $\mu$ S and Landsat OLI. Grounded on the findings we conclude that

- HyspIRI spectral setup is more robust and accurate in characterizing maize crops that growing under different levels of GLS disease infection when compared to Sentinel-2MSI, VEN $\mu \mathrm{S}$ and Landsat OLI.

- Sentinel-2 MSI could be a better alternative to HyspIRI considering that its spectral setup comparable performed in discriminating maize crops with different levels of GLS infections.

This study illustrates that HyspIRI hyperspectral remotely sensed data could be a panacea to the lack of spatial explicit spectral resolution data as a better alternative approach for accurate and effectively monitoring and forecasting agricultural crop diseases similar to the GSL, which are severe yield reduction agents.

\section{REFERENCES}

Al-Ahmadi, A. H., A. Subedi, G. Wang, R. Choudhary, A. Fakhoury and D. G. Watson, 2018. "Detection of charcoal rot (Macrophomina phaseolina) toxin effects in soybean (Glycine max) seedlings using hyperspectral spectroscopy." Computers and Electronics in Agriculture 150: 188-195.

Bégué, A., D. Arvor, B. Bellon, J. Betbeder, D. De Abelleyra, R. PD Ferraz, V. Lebourgeois, C. Lelong, M. Simões and S. R Verón, 2018. "Remote sensing and cropping practices: A review." Remote Sensing 10(1): 99.

Calderón, R., J. A. Navas-Cortés and P. J. Zarco-Tejada, 2015. "Early detection and quantification of Verticillium wilt in olive using hyperspectral and thermal imagery over large areas." Remote Sensing 7(5): 5584-5610.

Chaerle, L. and D. Van Der Straeten, 2000. "Imaging techniques and the early detection of plant stress." Trends in plant science 5(11): 495-501.

DAFF, 2018. Trends in the Agriculture Sector. D. o. A. F. a. F. (DAFF). Pretoria, DAFF: 135.

Dhami, N. B., S. Kim, A. Paudel, J. Shrestha and T. R. Rijal, 2015. "A review on threat of gray leaf spot disease of maize in Asia." Journal of Maize Research and Development 1(1): 71-85.

Dhau, I., E. Adam, O. Mutanga and K. K. Ayisi, 2018. "Detecting the severity of maize streak virus infestations in maize crop using in situ hyperspectral data." Transactions of the Royal Society of South Africa 73(1): 8-15. 
FAOSTAT, 2010. Statistical databases and data sets of the Food and Agriculture Organization of the United Nations.

Gao, F., M. C. Anderson, X. Zhang, Z. Yang, J. G. Alfieri, W. P. Kustas, R. Mueller, D. M. Johnson and J. H. Prueger, 2017. "Toward mapping crop progress at field scales through fusion of Landsat and MODIS imagery." Remote Sensing of Environment 188: 9-25.

Geis, J. P., 2014. "Application and timing effects of QoI and DMI fungicides and a foliar fertilizer on overall plant health and grain yield in corn."

Gevers, H., J. Lake and T. Hohls, 1994. "Diallel cross analysis of resistance to gray leaf spot in maize." Plant disease (USA).

Lee, C. M., M. L. Cable, S. J. Hook, R. O. Green, S. L. Ustin, D. J. Mandl and E. M. Middleton, 2015. "An introduction to the NASA Hyperspectral InfraRed Imager (HyspIRI) mission and preparatory activities." Remote Sensing of Environment 167: 6-19.

Lowe, A., N. Harrison and A. P. French, 2017. "Hyperspectral image analysis techniques for the detection and classification of the early onset of plant disease and stress." Plant methods 13(1): 80.

Mariotto, I., P. S. Thenkabail, A. Huete, E. T. Slonecker and A. Platonov, 2013. "Hyperspectral versus multispectral crop-productivity modeling and type discrimination for the HyspIRI mission." Remote Sensing of Environment 139(0): 291-305.

Marshall, M. and P. Thenkabail, 2015. "Advantage of hyperspectral EO-1 Hyperion over multispectral IKONOS, GeoEye-1, WorldView-2, Landsat ETM+, and MODIS vegetation indices in crop biomass estimation." ISPRS Journal of Photogrammetry and Remote Sensing 108: 205218.

Mee, C. Y., S. K. Balasundram and A. H. M. Hanif, 2017. "Detecting and Monitoring Plant Nutrient Stress Using Remote Sensing Approaches: A Review." Asian Journal of Plant Sciences 16: 1-8.

Mutanga, O., J. Van Aardt and L. Kumar, 2009. "Imaging spectroscopy (hyperspectral remote sensing) in southern Africa: an overview." South African Journal of Science 105(5-6): 193-198.

Nowell, D. C. 1996. Studies on ear rot and grey leaf spot of maize in South Africa. Doctor of Philosophy, University of Natal.

Pontius Jr, R. G. and M. Millones, 2011. "Death to Kappa: birth of quantity disagreement and allocation disagreement for accuracy assessment." International Journal of Remote Sensing 32(15): 4407-4429.

Shiferaw, B., B. M. Prasanna, J. Hellin and M. Bänziger, 2011. "Crops that feed the world 6. Past successes and future challenges to the role played by maize in global food security." Food Security 3(3): 307.

Tehon, L. and E. Daniels, 1925. "Notes on the parasitic fungi of Illinois: II." Mycologia 17(6): 240-249.

Thenkabail, P. S., I. Mariotto, M. K. Gumma, E. M. Middleton, D. R. Landis and K. F. Huemmrich, 2013. "Selection of hyperspectral narrowbands (HNBs) and composition of hyperspectral twoband vegetation indices (HVIs) for biophysical characterization and discrimination of crop types using field reflectance and Hyperion/EO-1 data." Selected Topics in Applied Earth Observations and Remote Sensing, IEEE Journal of 6(2): 427-439.

Thenkabail, P. S., R. B. Smith and E. De Pauw, 2002. "Evaluation of narrowband and broadband vegetation indices for determining optimal hyperspectral wavebands for agricultural crop characterization." Photogrammetric Engineering and Remote Sensing 68(6): 607-622.

Ward, J., E. Birch and D. Nowell, 1994. "Grey leaf spot on maize." Pietermaritzburg: Cedara Agric. Develop. Inst.

Ward, J. M., E. L. Stromberg, D. C. Nowell and F. W. Nutter Jr, 1999. "Gray leaf spot: a disease of global importance in maize production." Plant disease 83(10): 884-895.

Zhang, M., Z. Qin, X. Liu and S. L. Ustin, 2003. "Detection of stress in tomatoes induced by late blight disease in California, USA, using hyperspectral remote sensing." International Journal of Applied Earth Observation and Geoinformation 4(4): 295-310. 